\title{
EL LIBRO PERDIDO DE NEFTALÍ AGRELLA*
}

\author{
THE LOST BOOK OF NEFTALI AGRELLA
}

Roberto Lehnert Santander

Universidad de Antofagasta. Antofagasta, Chile

ana.gornall@uantof.cl

\begin{abstract}
C
uando Neftalí Agrella ${ }^{1}$ murió el 23 de marzo de 1957, sus amigos -pocos de ellos-, sus conocidos y sus hermanos en la poesía como González Zenteno, Angel Cruchaga Santa María, Luis Merino Reyes, Ester Matte Alessandri y otros de su tiempo, concurrieron al camposanto para despedir sus restos mortales.

Su vida, más bien reservada, era un misterio ya que muy pocos la conocían y pasó por ella, como el mismo dice, “... como el soplo de la ráfaga errante...”. Su esposa, Clementina Grandón Vásquez, con quien se casó en 1929, recuerda que "No traía amigos a la casa, quizás por su carácter tan especial, tan individualista y reservado. Discrepaba con sus compañeros de trabajo con frecuencia"².

Pero, ¿quién era, en verdad, Neftalí Agrella, nombre literario que adoptó, en definitiva? Al parecer, la vida del escritor estaba signada por el destino y rodeada de misterios e incógnitas de su vida personal y también de lo que sus comentaristas posteriores escribieron acerca de él.

Un año después de su nacimiento, su padre biológico muere como producto de un ataque de delírium tremens, resultado del alcoholismo, hecho
\end{abstract}

* El presente proyecto de investigación "Análisis de la producción literario-cultural de Neftalí Agrella, primer escritor de la ${ }^{a}$ Región de Antofagasta", se encuentra aprobado por Decreto Exento $\mathrm{N}^{\circ} 639$ de la Rectoría de la Universidad de Antofagasta con fecha 20 de junio de 2014.

${ }^{1}$ Neftalí Fructuoso de la Fuente Agrella (1896-1957).

${ }^{2}$ De la entrevista grabada el 3 y 4 de diciembre de 1982 a Clementina Grandón Vásquez, en Santiago. Material a publicar próximamente. 
que gravitará enormemente en el resto de su vida como un pesar hondo por no haber conocido a su padre. Pero, como todo niño que requiere de la guía de los mayores y de sentir la imagen materna y paterna, acepta, sin más, la figura de su padrastro, un ex-marino portugués que se había quedado en tierra luego de largas navegaciones por los mares del mundo. La dúctil personalidad del niño acumuló las historias del navegante creando fantasías de tormentas, naufragios y piratas que iban a participar de sus poemas y prosas en el futuro. Este hombre, Victorino D'Acunha Cordeiro, se iba a transformar en el héroe de Neftalí y el personaje principal de su gran poema elegíaco "El Capitán Abandonado" (1927-1935-1941), dividido en tres elegías, respectivamente.

Estudia en el Liceo de Valparaíso entre 1907 y 1909 cursando primero y segundo año básico para luego volver a Mejillones donde, con alrededor de doce años, comienza a trabajar en la gran maestranza de FF.CC. de los ingleses en ese puerto.

Agrella, en uno de los muchos fragmentos manuscritos que se poseen del escritor, dice: "1915. Estando en Mejillones, como mecánico en la Maestranza, envié a 'El Mercurio'3 que los domingos publicaba un Suplemento literario, un poema 'Urbi et Orbi' (Fragmento $\mathrm{N}^{\circ} 1$ )'. Este poema fue publicado, efectivamente, el día jueves 26 de agosto de 1915, convirtiéndose en su primera obra publicada de la que se tiene evidencia física, además de haber intentado su primer pseudónimo, Nephalí de Lafontaine y de haber cumplido dicho poema, hace poco, su primer centenario.

Este joven trabajador es mecánico, tornero y fundidor, inquieto, creativo y ansioso por las letras. Abandona su trabajo en la Maestranza, se va a Antofagasta, de allí salta a Valparaíso y ya en 1921 se embarca y navega hasta alcanzar Nueva York. Allí, frío, nieve, hambre y soledad pero, al fin y al cabo, la experiencia de salir al gran mundo y de conocer la otra vida, tan alejada de la tranquilidad pueblerina de su aldea costera. Regresa a Mejillones y aquí se inicia el rastreo de un libro enigmático que ha estado perdido por casi cien años y del cual se ha hablado mucho, se ha discutido su título y su contenido, pero nadie ha podido jamás entregar alguna respuesta concreta al respecto.

${ }^{3}$ Se refiere al periódico El Mercurio de Antofagasta. 
Dentro del FLA (Fondo Literario Agrella) se ha encontrado un ejemplar del libro perdido de Neftalí Agrella, tantas veces mencionado, tan buscado y nunca encontrado. Dicho libro se acerca casi a un mito por la repetición de lo que se ha dicho antes por otros comentaristas, poetas o amigos del desaparecido autor. El mismo autor -Agrella- mencionó una vez la existencia del libro. Luego, posteriormente, no figura, ni como mera alusión, algún dato de la existencia del libro. Se llega a pensar, a veces, que todo este asunto es un misterio pero el mismo Agrella, hablando en tercera persona, sostiene: "Vuelto a Antofagasta, hizo alguna labor en Mejillones donde, en una prensa de mano imprimió un pequeño libro, por primera vez en esa localidad. Eran versos revolucionarios".

Agrella regresa de los Estados Unidos un día 18 de marzo de 1921. El día 10 de abril del mismo año escribe un poema titulado "La Nueva Jornada". En el verso veinte de dicho poema, él escribe: "pero llevaré nueva savia de ensueño". Luego en la serie de Gouaches, en el número XLII, publicado en el diario El Abecé de Antofagasta, dice:

..."del modo que escribían mis antecesores como roja savia de Asoka,..." "Nueva savia” y "Roja savia" serán aludidas más adelante ( ${ }^{\circ}$ 199, 29 de abril de 1921, línea 22).

Entre los años 1921 y 1922, Agrella escribió un buen número de poemas sin que hubiera alguna alusión posterior al supuesto libro de 1921, publicado en Mejillones. En 1925 Agrella publica su libro Poemas y en él no hay ni presentación ni prólogo que pudiera dar alguna noticia sobre su producción literaria anterior a esa fecha o vinculada con el hipotético libro que se comenta. Se puede concluir, entonces, que en esos momentos, el libro Poemas es su primera publicación. Luego, después de un silencio de casi ocho años, se publica el segundo libro de Agrella en 1933, titulado El alfarero indio. En este libro, Julio Walton Hesse escribe, a modo de prólogo, "Apuntes para una biografía", la que, naturalmente, se refiere a la vida de Agrella hasta los 37 años de edad que cumplió ese año. Walton no se refiere para nada respecto de un libro que Agrella hubiera publicado en 1921; en otras palabras, Walton no tenía conocimiento de este hecho y Agrella jamás le confidenció algo respecto de él. En la contratapa posterior del libro $E l$ alfarero indio fue impreso un listado de diez obras de Agrella, la primera 
de las cuales es El alfarero indio, seguida de otras nueve, ninguna de las cuales tiene algo que la relacione con el libro supuestamente escrito por Agrella en 1921.

Alone (Díaz Arrieta), en La Nación del o7 de febrero de 1926, en su comentario acerca del libro Poemas, dado a conocer por Agrella, no añade nada respecto de otras publicaciones anteriores a la comentada por él. Julio Walton Hesse, amigo íntimo de Agrella y compañero de ruta en las lides literarias de varios años en Valparaíso, no dice una sola palabra respecto del libro misterioso. Esto parece bastante curioso ya que, dada la íntima amistad entre ambos, debería haber dado paso a una serie de datos y notas en torno a la vida de Agrella en Mejillones y, en especial, a su primer libro impreso allí. No ocurrió. O, simplemente, Agrella no deseaba recordar dicha experiencia literaria en razón de su alto nivel de exigencia y autocrítica personales o por su contenido crítico. Oreste Plath, contemporáneo cercano de Agrella, en su período de Valparaíso, publica en 1941 Poetas y poesía de Chile, donde entre las páginas 117 y 120 lo menciona. Señala que Neftalí nació en Antofagasta y, en general, se inspira en las notas que Walton escribiera como biografía de Agrella para componer algunos párrafos sin mayor novedad. Por supuesto, nada dice del libro fantasma.

Andrés Sabella en 1965 celebra los 40 años de la publicación de Poemas en 1925, en un recorte de diario que ha llegado sin otro dato. Este recuerdo lo hace ocho años después de la muerte de Agrella en 1957. Mario Bahamonde en su Antología del cuento nortino, 1966, incluye el cuento "El Alfarero Indio" (narración andina) y señala que Agrella nació en Mejillones. En 1973 Andrés Sabella escribe un artículo denominado "Hai Kai", en la revista Ercilla del 21 de marzo de dicho año, donde señala que Agrella nació en Mejillones en 1898; ambos datos, el lugar y la fecha son dudosos.

Sabella dice ".... en 1920 editó el único libro producido en sus imprentas (las de Mejillones, se entiende): Savia roja, conmovido por la muerte de José Domingo Gómez Rojas”. Por vez primera, de acuerdo a los antecedentes conocidos, se menciona un libro de Agrella impreso en Mejillones de título Savia roja del año 1920. Esto será importante ya que posteriores comentaristas repetirán el supuesto nombre del libro, el año y lugar de impresión, es decir, durante estos últimos 42 años se ha repetido, insistentemente, lo afirmado por Sabella. Santoro agrega que "Efraín Szmulewicz, en su Diccionario de la literatura chilena, publicado en 1977, donde men- 
ciona como la primera obra de Agrella Savia nueva, libro del cual da como única descripción la frase "poesía rebelde" (Santoro y Novoa, 2010: 29).

Andrés Sabella en La Estrella del Norte del día 7 de octubre de 1978, en un artículo titulado "El Espíritu de Mejillones", reitera lo señalado en otros comentarios. El mismo Sabella en El Mercurio de Antofagasta en su artículo "El Poeta de Mejillones", del 8 de octubre de 1978, señala que Agrella nació en Mejillones y afirma que "aprendió solo, en la paz de Mejillones, el inglés y el francés. Después hablaría japonés y se atrevería a cualquier aventura que le saliere al camino". No aporta ninguna otra información sobre el hipotético libro.

En el suplemento de El Mercurio de Calama del 15 de diciembre de 1978, Bahamonde recuerda que Agrella nació en Mejillones y que "muchos de sus libros permanecieron inéditos aun después de su muerte, condenados a un doloroso silencio definitivo". No hay ninguna otra información en este artículo que pudiera ser de utilidad para identificar al libro perdido.

Alfredo Aranda, crítico literario, escribe un comentario titulado "Nuestros Grandes Escritores" en El Mercurio de Antofagasta con fecha 17 de abril de 1982, donde se refiere a Neftalí Agrella, señalando a Mejillones como su ciudad natal. Repite, además, lo señalado por Sabella respecto de Agrella: "En 1920 publicó en Mejillones la única obra que quizás que se haya editado en dicho puerto: Savia roja, libro de poemas". Andrés Sabella en un artículo titulado "Neftalí Agrella", publicado en La Prensa de Tocopilla, el 6 de junio de 1982, reitera lo señalado respecto del poeta Agrella anteriormente.

Jorge Peralta Hidalgo, profesor-investigador del Instituto de Literatura Nortina e Investigaciones Etnoculturales de la Universidad de Antofagasta, publica un libro en 1983 titulado Neftalí Agrella, el cual presenta un estudio biográfico y literario del poeta. Respecto del tema en estudio, Peralta señala:

En 1920 publicó en Mejillones la única obra que quizás se haya editado en dicho puerto, Savia roja, en la que uno de sus poemas estaba dedicado a su amigo el poeta José Domingo Gómez Rojas, cuya trágica muerte le produjo una profunda tristeza; porque, como él, también había sufrido de una falta de comprensión anonadante (1983).

No hay nada nuevo en la reflexión de Peralta. 
Osvaldo Maya C. publica en 1999 el libro Espiral de humo en lo infinito, donde recoge las informaciones aportadas por Peralta -sin citarlo- y repite los puntos comunes respecto del tema que se investiga. Dice Maya: "Testimonio del primer decenio de sus creaciones será SAVIA ROJA (Mejillones 1920)". Se cierra esta primera parte con los aportes que presentan Wilfredo Santoro Cerda y Florentino Novoa Saavedra (2010) en el libro Poetas y pioneros, referidos a Mejillones.

Respecto del "primer libro", él maneja la hipótesis que uno podría ser Savia roja, lanzado en 1920; la otra opción sería Savia nueva, en 1921. Dicen Santoro y Novoa:

No se sabe qué portada tuvieron ni qué material contenían excepto un detalle. En el caso de Savia roja se dice que incluía un sentido homenaje de Agrella a su amigo, el poeta anarquista José Domingo Gómez Rojas, fallecido tras un motín juvenil en 1920 (2010).

Luego Santoro y Novoa añaden otro antecedente cronológico relativo al texto poético comentado:

Debe transcurrir hasta el año 2000 para que Savia nueva reaparezca siendo anunciado como el primer libro de Agrella, esta vez en la Antología crítica de la poesía chilena, de Naín Nómez (2010).

Como puede observarse, ahora se habla de Savia nueva, es decir, cada comentarista decide caprichosamente si es "roja" o "nueva" de acuerdo a su propia intuición. En verdad, nadie ha visto el libro, ni tampoco ha dado prueba concreta de su existencia hasta el presente.

Durante el año 1915, luego de un largo trabajo de revisión de 115 cartapacios del FLA, donde se habían distribuido, indiscriminadamente, los materiales donados por Clementina Grandón viuda de Agrella al Instituto, se ubicó en uno de ellos el libro tan buscado y citado por tantos críticos y comentaristas de la literatura nortina y nacional. Con ello se daba término a una larga búsqueda de 94 años desde su publicación en Mejillones en 1921 y a 58 años de la muerte de su autor. 


\section{Referencias}

Agrella, Neftalí. (s/f). Fragmentos $\mathrm{N}^{\circ}$ 1, 2, 3, 4, 5, 6. Manuscritos. . (1925). Poemas. Valparaíso: Imprenta Fisher.

Aranda. A. (1982). Nuestros grandes escritores. El Mercurio de Antofagasta, 17 de abril.

Bahamonde, M. (1966). Neftalí Agrella. En Antología del cuento nortino, pp. 140-147. Santiago: Editorial Universitaria. . (1978). Neftalí Agrella. El Mercurio de Calama, 15 de diciembre.

Díaz Arrieta, H. (Alone). (1926). Poemas por Neftalí Agrella. La Nación, o7 de febrero.

Grandón, C. (1982). Entrevista grabada a Clementina Grandón viuda de Agrella 3 y 4 de diciembre 1982. Santiago.

Maya, O. (1999). Espiral de humo en lo infinito. Antofagasta: NORprint.

Peralta, J. (1983). Neftalí Agrella. Antofagasta: Ediciones de la Universidad de Antofagasta.

Plath, O. (1941). Poetas y poesía de Chile (pp. 117-120). Santiago: Talleres Gráficos La Nación.

Sabella, A. (1965). Los poemas de Neftalí Agrella. El Mercurio de Antofagasta. . (1973). Hai Kai. Ercilla, 1966, 21 de marzo. . (1978). El espíritu de Mejillones. La Estrella del Norte. Antofagasta, 7 de octubre

. (1978). El Poeta de Mejillones. El Mercurio de Antofagasta, 8 de octubre.

(1982). Neftalí Agrella. La Prensa de Tocopilla, 6 de junio.

Santoro, W. y Novoa, F. (2010). Poetas y pioneros. Antofagasta: Emelnor Editores.

Walton, J. (1933). Apuntes para una biografía. En N. Agrella, El alfarero indio (pp. II-III-IV-V). Santiago: Talleres Gráficos Cóndor. 